\title{
CLÁUSULA DE RESERVA do POSSÍvEL E A LIMITAÇÃo À GARANTIA CONSTITUCIONAL DE PLENO ACESSO À SAÚDE
}

\author{
POSSIBLE RESERVE CLAUSE AND THE LIMITATION ON THE CONSTITUTIONAL \\ GUARANTEE OF FULL HEALTH ACCESS
}

Horígenes Fontes Soares Neto ${ }^{1}$

\section{RESUMO}

As discussões em torno das ações públicas no setor dos direitos sociais remanescem no cenário jurídico com expressiva significância. Por assim ser, mesmo que apresentados na Carta Política de 1988 como fundamentais, estas diretrizes têm sofrido para sua implementação barreiras impostas por restrições orçamentárias justificadas na cláusula da reserva do possível, é o caso da garantia social à saúde. Diante do fato em apreço, fundado que é o sistema constitucional brasileiro nos princípios da dignidade humana, mínimo existencial e vedação do retrocesso, propõe-se neste ensaio a análise da contraposição entre a reserva do possível e o direito à saúde, pesquisando-se, por meio de revisão de literatura e análise jurisprudencial, abordadas qualitativamente, se a interferência daquela cláusula possibilita a inefetividade desta garantia.

PALAVRAS-CHAVE: Saúde. Mínimo existencial. Reserva do possível.

\begin{abstract}
The discussions about public actions in the social rights sector remain in the legal scenario with significant significance. Thus, even if presented in the Political Charter of 1988 as fundamental, these guidelines have suffered for their implementation barriers imposed by budget constraints justified in the clause of the possible reserve, is the case of social guarantee to health. In view of this fact, based on the fact that the Brazilian constitutional system is based on the principles of human dignity, the existential minimum and the prohibition of retrocession, it is proposed in this essay the analysis of the contraposition between the reserve of the possible and the right to health, through a literature review and jurisprudential analysis, approached qualitatively, if the interference of that clause allows the ineffectiveness of this guarantee.
\end{abstract}

KEYWORDS: Health. Existential minimun. Reserve of the possible.

\footnotetext{
${ }^{1}$ Mestrando no Programa de Pós-Graduação em Economia Regional e Políticas Públicas (PERPP) pela Universidade Estadual de Santa Cruz (UESC). Especialista em Direito Público pela Faculdade Damásio de Jesus. Bacharel em Direito pela IUNI Educacional - UNIME Itabuna. Especialista em Prática Trabalhista e Processual Civil pela Faculdade Independente do Nordeste (FAINOR). Advogado. Docente do Curso de Direito da IUNI Educacional - UNIME Itabuna. Conciliador do Tribunal de Justiça da Bahia.
} 


\section{INTRODUÇÃO}

Frente à transição pela qual passou o Estado brasileiro para o processo de redemocratização, a Constituição Cidadã de 1988, pautada em premissas de garantia do mínimo existencial, como as oriundas da Declaração Universal de Direitos Humanos de 1948, bem assim da Convenção Americana de Direitos Humanos (Pacto de San José da Costa Rica) de 1969, fez inserir em seu texto direitos cuja observância e resguardo se tornaram obrigatórios, seja por parte dos indivíduos, seja por parte do Estado (MENDES; BRANCO, 2012).

Nesta linha de raciocínio, desde o preâmbulo, o constituinte originário buscou solidificar o contexto político moderno do Brasil por meio da asseguração pelo poder público do exercício pleno dos direitos fundamentais, mormente em razão da necessidade de estruturar sob estas bases um Estado Democrático que se erguia, longe do autoritarismo e da violência à condição humana dos sujeitos de direitos vigente em tempos anteriores.

Segundo Bulos (2012, p. 522), "sem os direitos fundamentais o homem não vive, não convive, e, em alguns casos, não sobrevive", de modo que representam, nas palavras do autor, "um conjunto de normas, princípios, prerrogativas, deveres e institutos, inerentes à soberania popular, que garantem a convivência pacífica, digna, livre e igualitária, independentemente de credo, raça, origem, cor, condição econômica ou status social".

Sob tal ótica, é nítida a vontade do legislador na proteção dos direitos inerentes à condição humana, os quais se espalham por toda a Carta Maior tomando formas claras e expressivas entre os art. $5^{\circ}$ e 17 do diploma em referência e se mantendo sob a roupagem de cláusulas pétreas (direitos que não podem a lei ou o poder constituinte derivado suprimirem) pela interpretação extensiva do art. 60, §4ำ, IV, da Carta Política de 1988.

Não se olvida, entretanto, que para atingir o papel de sua criação tais garantias de primeira ordem dos indivíduos devam perpassar pela observância de princípios que the dão forma e modelo ou que o limitam, em especial quando se busca, pelas vias do Judiciário, a resolução de embate firmado entre a concessão do direito e a limitação do erário, como nas querelas cuja matéria versa sobre a saúde. 
Por assim ser, diante do forte conteúdo principiológico que norteia a legislação nacional, este ensaio objetiva, por meio do método hipotético-dedutivo e da abordagem qualitativa, estruturados sob uma revisão de literatura fundada em obras e artigos científicos do Direito Constitucional moderno, além do cotejo à jurisprudência oriunda dos Tribunais Superiores, analisar a relação hodierna firmada entre a garantia constitucional de acesso à saúde e a reserva do possível, perquirindo se em face da existência de limitação trazida pela referida cláusula ao direito constitucional analisado, acentua-se a inefetividade desta garantia.

\section{DIREITOS SOCIAIS E OS PRINCÍPIOS NA ÓTICA CONSTITUIÇÃO DE 1988}

Em razão da importância que possuem, os direitos fundamentais guardam em seu seio matrizes principiológicas cuja expressão não só lhes abarca, mas serve a toda a regulação do sistema jurídico brasileiro.

Dentre os inúmeros princípios umbilicalmente ligados à temática, incumbe apontar para este estudo a dignidade humana e a proibição do retrocesso social.

Norte de todo o ordenamento jurídico nacional, o princípio da dignidade humana ganhou força e rosto no panorama constitucional brasileiro a partir da Constituição de 1988, a qual no art. 1ํㅡㄴ III, já o anuncia enquanto fundamento da República Federativa do Brasil.

Decorrência dos diplomas internacionais já citados na introdução do estudo, inspirados no combate às violações praticadas durante a Segunda Guerra Mundial, a exemplo da tortura, o princípio da dignidade humana denota a relevância da proteção às garantias basilares dos indivíduos, sem as quais nenhum outro direito há, servindo, portanto, ao mesmo tempo, de norma motriz, metanorma, princípio e regra.

Nas palavras de Novelino (2012, p. 379)

Dentre os fundamentos do Estado brasileiro, a dignidade da pessoa humana possui um papel de destaque. Núcleo axiológico do constitucionalismo contemporâneo, a DPH é o valor constitucional supremo que irá informar a criação, a interpretação e a aplicação de toda a ordem normativa constitucional, sobretudo, o sistema dos direitos fundamentais. 
Completa o mesmo autor ao dizer que dignidade humana e direitos fundamentais são elementos indissociáveis de modo a que:

A dignidade é o fundamento, a origem e o ponto comum entre os direitos fundamentais, os quais são imprescindíveis para uma vida digna. Nas palavras de Jürgen HABERMAS, "a dignidade humana, que é uma e a mesma em toda parte e para todos, fundamenta a indivisibilidade de todas as categorias de direitos humanos. Só em colaboração uns com os outros podem os direitos fundamentais cumprir a promessa moral de respeitar igualmente a dignidade humana de cada pessoa". (NOVELINO, p. 383)

Não é demais lembrar que ao enunciar a dignidade humana como princípio conformador do sistema constitucional brasileiro e intrínseco aos direitos fundamentais, não se olvida a representação fática efetiva que deve ter este nos casos concretos. De nada adianta o anúncio da dignidade sem que ao lado exista a garantia patente do mínimo existencial a quem dela se arroga. Sendo assim, não à toa, mescla-se a dignidade humana ao princípio do mínimo existencial quando se tratam dos direitos fundamentais/sociais, sobretudo porque não se fala de um dissociado do outro.

Por mínimo existencial se entende a concessão aos indivíduos das condições basilares para a sobrevivência. No cenário constitucional brasileiro, a doutrina lê tal diretriz com os olhos dos direitos individuais e sociais, delimitados pelas gerações de direitos humanos estatuídas por Vasak nos fins dos anos 1970, para quem, à época, existiam três dimensões de direitos: na primeira, os direitos de liberdade (civis e políticos); na segunda, os de igualdade (sociais, econômicos e culturais); na terceira, os de fraternidade (paz e autodeterminação dos povos).

A partir disto, o mínimo existencial é observado junto à dignidade humana como parte integrante desta e cuja atenção deve ter sobre si recaída, uma vez que, nos dizeres de Sarlet e Zockun (2016, p. 125)

[...] remete-se à noção de que a dignidade da pessoa humana somente estará assegurada - em termos de condições básicas a serem garantidas pelo Estado e pela sociedade - onde a todos e a qualquer um estiver assegurada nem mais nem menos do que uma vida saudável. De outra parte, até mesmo a diferença entre o conteúdo do direito à vida e da dignidade da pessoa humana, que, a despeito dos importantes pontos de contato, não se confundem, poderá vir a ser negligenciada. 
Dignidade humana e mínimo existencial, portanto, são matrizes que não se deve esquecer quando a discussão toca os direitos fundamentais.

Junto ao princípio da dignidade humana, também de forte significância no contexto dos direitos fundamentais é o princípio da proibição ao retrocesso social.

Uma vez garantidos direitos ao indivíduo, na forma de condições essenciais ao seu pleno exercício de vida, incorporam-se-lhe ao patrimônio jurídico e daí não podem ser retirados, eis que, se assim fosse, garantias constitucionalmente previstas retroagiriam em malefício dos sujeitos.

Segundo anota Vasconcelos (2013, p. 122), "defende-se, com efeito, que o princípio da proibição de retrocesso social é um princípio constitucional, com índole retrospectiva, na medida em que tem por fim a manutenção de algumas conquistas sociais, econômicas e culturais, indo contra a sua restrição ou supressão arbitrárias".

Neste ínterim, diante de uma ordem constitucional que assegura direitos e não os suprime, a vedação ao retrocesso social é matriz que se espraia por todo o âmbito normativo, de sorte que sua aplicabilidade se estende a todos os dispositivos assecuratórios de direitos, em especial os que asseveram os sociais.

O Supremo Tribunal Federal, por diversas vezes, já afirmou a relevância do princípio em comento no sistema constitucional, salientando que, estipulada norma garantidora de direitos, não pode o poder público deixar de aplicá-la, omitindo-se ao texto, sob pena de inconstitucionalidade por omissão. Veja-se, exemplificativamente, ementa de acórdão do Ag. no RE 639.337/SP abordando a temática:

CRIANÇA DE ATÉ CINCO ANOS DE IDADE - ATENDIMENTO EM CRECHE E EM PRÉ-ESCOLA - [...] OBRIGAÇÃO ESTATAL DE RESPEITAR OS DIREITOS DAS CRIANÇAS - EDUCAÇÃO INFANTIL - DIREITO ASSEGURADO PELO PRÓPRIO TEXTO CONSTITUCIONAL (CF, ART. 208, IV, NA REDAÇÃO DADA PELA EC № 53/2006) [...] DIGNIDADE DA PESSOA HUMANA E VEDAÇÃO DO RETROCESSO SOCIAL [...] A PROIBIÇÃO DO RETROCESSO SOCIAL COMO OBSTÁCULO CONSTITUCCIONAL À FRUSTRAÇÃO E AO INADIMPLEMENTO, PELO PODER PÚBLICO, DE DIREITOS PRESTACIONAIS. - O princípio da proibição do retrocesso impede, em tema de direitos fundamentais de caráter social, que sejam desconstituídas as conquistas já alcançadas pelo cidadão ou pela formação social em que ele vive. - A cláusula que veda o retrocesso em matéria de direitos a prestações positivas do Estado (como o direito à educação, o direito à saúde ou o direito à segurança pública, v.g.) traduz, no processo de efetivação desses direitos fundamentais individuais ou coletivos, obstáculo a que os níveis de concretização de tais prerrogativas, uma vez atingidos, venham a ser ulteriormente reduzidos ou suprimidos pelo Estado. Doutrina. Em consequência 
desse princípio, o Estado, após haver reconhecido os direitos prestacionais, assume o dever não só de torná-los efetivos, mas, também, se obriga, sob pena de transgressão ao texto constitucional, a preservá-los, abstendo-se de frustrar mediante supressão total ou parcial - os direitos sociais já concretizados. [...] (STF, Ag. no RE 639.337/SP, Min. Rel. Celso de Mello, DJe: 15/09/2011).

Perceba-se que o princípio em espeque assume dupla face. Cabe ao Estado não somente se abster da supressão de direitos já garantidos, mas também de atuar positivamente para que tais normas possam ser visualizadas e aplicadas no mundo fático, com destaque para os direitos sociais.

É, portanto, sob tal espeque que sustentam as garantias sociais na ordem constitucional vigente.

Fortemente influenciada pela industrialização que sustentava a economia dos séculos XVIII e XIX e negligenciava condições basilares de vida humana, a exemplo de cuidados com a saúde e o labor, extraindo-se a empresa excessivamente do trabalhador a mais-valia, fatores até então conformadores dos extratos sociais, exigia-se do Estado maior atenção, em especial pela forte noção de igualdade remanescente da Revolução Francesa de 1789.

Tecidos, pois, na necessidade de atuação positiva do Estado como direitos humanos de segunda geração, voltados à referida isonomia, no sentido material do termo, o olhar legislativo para os direitos sociais remonta-se ao início do século XX, cujo pontapé fora dado pelas Constituições Mexicana, de 1917, e Alemã, de 1919, marcos reconhecidamente tomados pela doutrina e representativos dos direitos sociais, econômicos e culturais (TOLFO, 2013).

Segundo Agra (2012, p. 158), "os direitos de segunda dimensão produzem uma simbiose entre o Estado e a sociedade, propiciando que a igualdade saia da esfera formal e adentre na esfera material, garantindo direitos a todos, principalmente àquela parte da população que é carente de recursos".

No Brasil, nomeadamente, desde as Cartas de 1930, alguns dos direitos de segunda dimensão já se previam no prisma constitucional, mas, é com a forma de Estado Democrático de Direito e a Cidadã de 1988 que as garantias sociais tomam corpo e se tornam cláusulas insuprimíveis por lei ou ato normativo que apenas reforme o texto constitucional (SARLET; MARINONI; MITIDIERO, 2012). 
Previstas expressamente nos arts. 60 a 11 da Constituição Federal de 1988, representaram, e ainda na atualidade representam, rol exemplificativo de direitos (SARLET; MARINONI; MITIDIERO, 2012) por meio dos quais o constituinte originário buscou assegurar garantias que, em uma nova ordem jurídica que se apresentava, outorgassem aos cidadãos a dignidade necessária ao exercício da vida. Dentre aqueles reputados de maior significância, merecedores, portanto, de indicação manifesta na Carta Maior, elencaram-se, nesta ordem, educação, saúde, alimentação, trabalho, moradia, lazer, segurança, previdência social, proteção à maternidade, proteção à infância e assistência aos desamparados.

Nas palavras de Paulo e Alexandrino (2015, p. 247), "os direitos sociais constituem liberdades positivas, de observância obrigatória em um Estado Social de Direito, tendo por objetivo a melhoria das condições de vida dos hipossuficientes, visando à concretização da igualdade social". Em iguais passos, afirma Agra (2012, p. 280-281):

De forma bastante genérica, pode-se dizer que o fator teleológico dos direitos sociais é a proteção dos hipossuficientes estatais, a redistribuir os ativos materiais para que a população possa ter uma vida condigna e de criar um Welfarestate, forcejando a criação de uma justiça equitativa. Personificam a principal ferramenta de que dispõe o Estado para a realização da justiça distributiva, em que os entes estatais auxiliam os cidadãos carentes de recursos mínimos para sua subsistência ou que possam cair na marginalidade social ou que não possam obter por conta própria esses bens ou serviços em qualidade razoável. Por essa razão não é possível o retrocesso das normas que os definem, a não ser em virtude da existência de motivos plausíveis.

Por tais linhas, exalta-se a importância dos direitos sociais na ordem constitucional para a asseguração da isonomia e do mínimo existencial, bem como da proibição do retrocesso aos direitos da coletividade já suscitada neste estudo.

\section{SAÚdE COMO EXPRESSÃo do MíNIMO EXISTENCIAL E A CLÁUSULA DE RESERVA DO POSSÍVEL}


Elencado entre os direitos sociais considerados de maior relevância, ao lado da educação e segurança pública, a efetividade do direito à saúde representa a garantia do mínimo existencial.

Preliminarmente, deve-se antes de adentrar ao mérito de qualquer discussão a respeito da asseguração de tal direito social, tecer breves considerações sobre o que é saúde.

Segundo denota Silva (s.d), a definição de saúde sofreu inúmeras modificações ao longo do tempo, reorientando-se historicamente. Neste ponto, o conceito do termo incialmente abarcou a ideia de ausência de doenças (físicas ou espirituais) e, a partir daí, reorientou-se diante da evolução social.

Para cada um dos instantes históricos tem-se um conceito, de maneira que é com o ápice da Revolução Industrial, em meados do século XX, que as discussões de significado da expressão se acentuaram.

Silva (s.d, p. 10) advoga que

O ambiente social do fim do século passado e primeira metade do século $X X$, auge da Revolução Industrial, propiciou o debate entre as duas grandes correntes que buscaram conceituar a saúde. De um lado, grupos marginais ao processo de produção que viviam em condições de vida miseráveis, enfatizavam a compreensão da saúde como diretamente dependente de variáveis relacionadas ao meio ambiente, ao trabalho, à alimentação e à moradia. A incidência de tuberculose, por exemplo, era acentuadamente mais elevada nas camadas sociais com menos renda. Por outro lado, a descoberta dos germes causadores de doença e seu subsequente isolamento, que possibilitou o desenvolvimento de remédios específicos, falava a favor da conceituação da saúde como ausência de doenças.

No fim da Segunda Guerra Mundial, entretanto, que politicamente o conceito outrora discutido se apazigua. Com o nascimento da Organização das Nações Unidas e, junto a ela, da Organização Mundial da Saúde - OMS, em 1948, inspiradas em instrumentos normativos internacionais que garantiam a primazia do bem-estar, a saúde, em notas mundiais, passou a significar "o estado de completo bem-estar físico, mental e social e não apenas a ausência de doença".

Apesar de aparentemente utópico, em especial porque a saúde se sujeita a elementos não passíveis de controle ou estabilidade e devido as mudanças corriqueiras, 
inerentes à vida humana, quis-se com o conceito sinalizar um compromisso assumido pelas nações do mundo com a manutenção da dignidade humana.

De acordo Abreu et. al. (s.d., p. 65), "a própria compreensão de saúde tem também alto grau de subjetividade e determinação histórica, na medida em que indivíduos e sociedades consideram ter mais ou menos saúde dependendo do momento, do referencial e dos valores que atribuam a uma situação".

Nos moldes atuais da OMS tem-se buscado conceituar a saúde da maneira mais dinâmica possível, intentando abarcá-la em um significado mais próximo do real. Por assim ser, Abreu et. al. (s.d., p. 65) insiste que

\begin{abstract}
Diversas tentativas vêm sendo feitas a fim de se construir um conceito mais dinâmico, que dê conta de tratar a saúde não como imagem complementar da doença e sim como construção permanente de cada indivíduo e da coletividade, que se expressa na luta pela ampliação do uso das potencialidades de cada pessoa e da sociedade, refletindo sua capacidade de defender a vida. [...] nenhum ser humano (ou população) será totalmente saudável ou totalmente doente. Ao longo de sua existência, viverá condições de saúde/doença, de acordo com suas potencialidades, suas condições de vida e sua interação com elas.
\end{abstract}

Entretanto, apesar da cota de responsabilidade socialmente assumida, o Estado, historicamente, adquiriu a condição de principal mantenedor das condições básicas de vida saudável de sua população. No Brasil não foi diferente.

Desde o início da organização do Estado brasileiro a preocupação com a saúde já se apresentava pedra de toque. As Santas Casas de Misericórdia e os "socorros públicos", instalados logo no Brasil Império, importantes instrumentos assistencias a este ramo eminentemente público, simbolizavam as primeiras marcas de atenção com a saúde.

Todavia, é com a Carta Federal de 1988 que o direito à saúde ganha efetiva proteção jurídico-constitucional. Considerada um dos ramos da seguridade social, conforme art. 194, CF/1988, caracterizada, em destaque, pelos objetivos da universalidade da cobertura e do atendimento, uniformidade e equivalência na prestação dos benefícios e serviços às populações urbanas e rurais, bem assim pela seletividade e distributividade dos benefícios e serviços, demonstra-se essencial à existência humana.

Inaugurada no art. 196, CF/1988, a saúde no Brasil é "direito de todos e dever do Estado, garantido mediante políticas sociais e econômicas que visem à redução do risco 
de doenças e de outros agravos e ao acesso universal e igualitário às ações e serviços para sua promoção, proteção e recuperação".

Cada elemento trazido no citado artigo guarda relevância em seu significado. Em razão disto, Mendes e Branco (2012) esmiúçam-nos e cabe neste estudo fazê-lo de igual modo.

Dizer "direito de todos" é asseverar que tal ramo da seguridade, como apontou o Ministro do Supremo Tribunal Federal Celso de Mello, no AgR-RE n. 271.286-8/RS, "é direito subjetivo assegurado à generalidade, que conduz o indivíduo e o Estado a uma relação jurídica obrigacional. [...] Há um direito subjetivo público a políticas públicas que promovam, protejam e recuperem a saúde" (MENDES; BRANCO, 2012, p. 696-697).

O "dever do Estado" assinala que os entes da federação se responsabilizam pela prestação da saúde, viabilizando sua existência e manutenção. Não à toa, o art. 23, II, CF/1988, impõe-na como dever comum a todos eles.

Falar "garantido mediante políticas sociais e econômicas" significa ressalvar a necessidade de elaboração de ações estatais que viabilizem a prestação do direito indicado por meio do emprego de recursos suficientes para tal finalidade.

O desenvolvimento de "políticas que visem à redução do risco de doença e de outros agravos" labora com o sentido preventivo das ações de saúde. A Carta Constitucional evoca a necessidade de priorizar a prevenção (art. 198, II) e, para isto, exige uma atuação ampla dos serviços no setor, o que engloba não só a saúde propriamente dita (seja individual ou coletiva), mas também o serviço de saneamento básico e distribuição de água potável como forma de evitar o alastramento de doenças e contaminações.

O "acesso universal e igualitário" das políticas de saúde reafirma os princípios securitários da universalidade do atendimento e da uniformidade na prestação de serviços já escritos neste estudo. A saúde deve ser o mais abrangente possível e, para além, não deve diferenciar-se na prestação, de maneira que a capacidade econômica individual é insignificante no que se refere à assistência prestada pelo ramo.

Por fim, não menos relevante, é dizer que o Estado deve nas ações e serviços de saúde atuar para a "promoção, proteção e recuperação" desta, o que, segundo Mendes e Branco (2012, p. 698) no 
estudo do direito à saúde no Brasil leva a concluir que os problemas de eficácia social desse direito fundamental devem-se muito mais a questões ligadas à implementação e manutenção das políticas públicas de saúde já existentes - o que implica também a composição dos orçamentos dos entes da federação - do que à falta de legislação específica. Em outros termos, o problema não é de inexistência, mas de execução (administrativa) das políticas públicas pelos entes federados. [...] o direito à saúde há de se efetivar mediante ações específicas (dimensão individual) e mediante amplas políticas públicas que visem à redução do risco de doença e de outros agravos (dimensão coletiva). Nessas perspectivas, as pretensões formuladas e formuláveis tanto poderão dizer respeito a atos concretos como a políticas e ações administrativas que contribuam para a melhoria do sistema de saúde, incluídas aqui normas de organização e procedimento.

Inegável, deste modo, a necessidade de atenção e proteção do Estado a tal garantia fundamental, a qual se encontra intensamente restringida pela reserva do possível.

Tecido no seio da administração pública como aquele responsável por atender às barreiras econômicas impostas ao erário, a cláusula da reserva do possível tem servido de argumento para a não prestação da saúde adequada pelos governos.

Conceitualmente entende-se que tal cláusula significa analisar o binômio necessidade-possibilidade na tomada de decisões em direitos sociais no âmbito do Estado, ou seja, no compasso do princípio da seletividade e distributividade, previsto no parágrafo único do art. 194, CRFB/1988, ao ente administrativo só se permite a concessão do direito se financeiramente possível.

Não se olvida a limitação orçamentária do poder público na asseguração dos direitos sociais previstos na Constituição de 1988, entretanto, segundo denotam Matsuda, Pereira e Souza (s.d), o uso da reserva do possível não é apto a deslegitimar o dever assumido pelo Estado no atendimento universal deste direito previsto nos arts. 194 e 196, do diploma constitucional.

Esquece-se a administração pública de que sob manto dos princípios que norteiam o sistema jurídico brasileiro, em destaque os anotados neste ensaio, deve-se garantir a quem necessite de atendimento amplo e eficaz suporte por meio de políticas governamentais no âmbito da saúde.

Por expressão do mínimo existencial, não se pode arvorar o discurso infundado da ausência de recursos públicos como fundamento à omissão do Executivo. É de destacar, 
neste sentido, que não se tratam os direitos fundamentais, mormente os sociais, como folha de papel ou norma meramente programática, mas, muito além disto, compromisso afiançado pela administração e obrigação imposta pela Carta Política de 1988.

A Suprema Corte, por oportuno, já teve a possibilidade de se posicionar sobre a reserva do possível e o dever de assistência aos direitos sociais por meio do Estado, afirmando:

[...] A questão da reserva do possível: reconhecimento de sua inaplicabilidade, sempre que a invocação dessa cláusula puder comprometer o núcleo básico que qualifica o mínimo existencial (RTJ 200/191-197). O papel do Poder Judiciário na implementação de políticas públicas instituídas pela Constituição e não efetivadas pelo poder público. A fórmula da reserva do possível na perspectiva da teoria dos custos dos direitos: impossibilidade de sua invocação para legitimar o injusto inadimplemento de deveres estatais de prestação constitucionalmente impostos ao poder público. A teoria da "restrição das restrições" (ou da "limitação das limitações"). Caráter cogente e vinculante das normas constitucionais, inclusive daquelas de conteúdo programático, que veiculam diretrizes de políticas públicas, especialmente na área da saúde (CF, arts. 6o, 196 e 197). (STF, STA 223 AgR, rel. min. Celso de Mello, j. 14-4-2008, P, DJE de 9-4-2014).

Da relevância, pois, que exprimem na ordem jurídica, a garantia dos direitos da coletividade, albergados como fundamentais, afigura-se foco de proteção por parte do Estado, o qual, pela evolução social, não pode apagá-los ou esquecê-los sob o argumento preliminar e, por mais das vezes, desarrazoado, da escassez de recursos públicos, mas, de outra banda, garantir-Ihes a máxima efetividade e aplicabilidade, para que não se esvaziem seus conteúdos. Assim reiteradamente vem assinalando a jurisprudência o caso da saúde:

REEXAME NECESSÁRIO. FORNECIMENTO DE MEDICAMENTOS. RESPONSABILIDADE SOLIDÁRIA DE TODOS OS ENTES DA FEDERAÇÃO. INOPONIBILIDADE DA RESERVA DO POSSÍVEL. TEORIA DO MÍNIMO EXISTENCIAL. PRECEDENTES DO STF E DO STJ. SENTENÇA MANTIDA. 1.0 fornecimento de medicamentos pelo Estado decorre do dever insculpido no artigo 196 da Constituição da República, ensejando responsabilidade solidariamente compartilhada por todos os entes da Federação. 2.Inoponibilidade da teoria da reserva do possível ou de que a droga em questão não integra mais a lista de medicamentos gratuitamente disponibilizados pela suspensão do convênio com a clínica que aplica a droga, sob pena de se admitir restrições orçamentárias ao direito à vida e à saúde. 3.O Poder Público não pode se furtar a garantir aos cidadãos o mínimo essencial para sua sobrevivência. Teoria do mínimo existencial. 4. Reexame necessário improvido. (TJ-AM 06049999720168040001 AM 060499997.2016.8.04.0001, Relator: Maria do Perpétuo Socorro Guedes Moura, Data de Julgamento: 02/04/2018, Segunda Câmara Cível). 
CONSTITUCIONAL. ADMINISTRATIVO. PROCESSUAL CIVIL. DISPONIBILIZAÇÃO DE LEITO DE UTI. DIREITO À SAÚDE E À VIDA DIGNA. DEVER DO ESTADO. RESERVA DO POSSÍVEL E MÍNIMO EXISTENCIAL. IMPOSSIBILIDADE DE DISSOCIAÇÃO. 1.Caracterizada a violação a direito líquido e certo, assegurado no art. 196 da Constituição Federal, o Mandado de Segurança revela-se, indiscutivelmente, a via adequada para a proteção desse direito. 2. A disponibilização do leito de UTI objetiva assegurar o direito à saúde e à vida da paciente, constitucionalmente garantidos. 3. Direito fundamental, de aplicação imediata e dever do Estado, previstos na Constituição Federal (arts. 5을 caput e $\S$ 1ํ, 6ํㅜ e 196). 4. A "reserva do possível" nunca pode estar dissociada do "mínimo existencial", pois somente depois de atendido o mínimo existencial, aí incluído o direito à saúde, é que o Poder Público terá discricionariedade para cogitar a efetivação de outros gastos. 5.Precedentes do STF, do STJ e desta Corte. 6.Segurança concedida. Liminar ratificada. ACÓRDÃO Vistos, relatados e discutidos estes autos, acorda o Órgão Especial do Tribunal de Justiça do Estado do Ceará, por maioria em conceder a segurança requestada, nos termos do voto do relator. PRESIDENTE TJCE Presidente do Órgão Julgador Exmo. Sr. JUCID PEIXOTO DO AMARAL Relator MINISTÉRIO PÚBLICO. (TJ-CE 06286882220168060000 CE 0628688-22.2016.8.06.0000, Relator: JUCID PEIXOTO DO AMARAL, Data de Julgamento: 15/02/2018, Órgão Especial, Data de Publicação: 15/02/2018)

Os Colegiados, deste modo, firmes, elevam o direito à saúde à essencialidade de que desfruta no sistema jurídico-político-coletivo, acentuando sua significância e relação intrínseca como mínimo existencial, bem como afastando, em muitos casos, a tese estatal da ausência de recursos públicos a assisti-lo.

\section{CONSIDERAÇÕES FINAIS}

Sobreleva no ordenamento jurídico nacional a importância dos direitos sociais, tidos pela jurisprudência e doutrina como uma das expressões dos direitos fundamentais.

Não sem razão, diante desta relevância que ostentam, em especial por seu caráter de atenção ao mínimo existencial, fator que conforma e perfectibiliza a dignidade humana, não podem sofrer com as ingerências de um Estado que, arrogando-se da ausência de recursos originária da patente má-administração de fundos, deixa de prestar garantias tão essenciais à sobrevivência humana.

Neste contexto, o direito à saúde se insere como norma motriz da sistemática de segurança aos riscos e contingências que acometem os indivíduos e sociedade, e cuja proteção deve ser assegurada, em primeiro plano, pelo poder público. 
A fragilidade da cláusula da reserva do possível, erigida sem fundamentos pelo poder público, não deve ser capaz de se opor àquilo que de basilar o texto constitucional oferta ao ser humano, condições de vida dignas e saudáveis. Do contrário, legitimar-se-ia o retrocesso social, o desrespeito à Constituição e o enfraquecimento do direito social à saúde em contramão da norma, tornando-o sem efetividade no mundo fático.

Para isto, deve o Poder Judiciário, como guardião da sistemática jurídica, zelar para que não haja abuso de poder pelos governos que, inobstante a possibilidade, deixam de atender a quem dele necessita, em clara afronta ao princípio da universalidade da cobertura e do atendimento, norte da seguridade social.

Saúde, embora ramo que perpassa o público e o privado, é dever indissociável do Estado.

\section{REFERÊNCIAS}

ABREU, Ana Rosa et. al. (Coord.). Saúde. Brasília: FNDE, s.d.

AGRA, Walber de Moura. Curso de Direito Constitucional. 7. ed. Rio de Janeiro: Forense, 2012.

BRASIL. Tribunal de Justiça do Amazonas. Acórdão nos autos do processo de no 0604999-97.2016.8.04.0001. 2a Câmara Cível. Relator: Des. Maria do Perpétuo Socorro Guedes Moura. Julgamento: 02 abr. 2018. Disponível em: <https://tjam.jusbrasil.com.br/jurisprudencia/583175717/6049999720168040001-am-06049999720168040001>. Acesso em: 26 out. 2018.

BRASIL. Tribunal de Justiça do Ceará. Acórdão nos autos do processo de no 062868822.2016.8.06.0000. Órgão Especial. Relator: Des. Jucid Peixoto do Amaral. DJ: 15 fev. 2018. Disponível em: <https://tjce.jusbrasil.com.br/jurisprudencia/579078275/6286882220168060000-ce-06286882220168060000 >. Acesso em: 26 out. 2018.

BRASIL. Supremo Tribunal Federal. Agravo no Recurso Extraordinário no 639.337/SP. 2 $2^{\text {a }}$ Turma. Relator: Min. Celso de Mello. DJe: 15 set. 2011. In: Informativo STF, 2011. Disponível em: $<$ http://redir.stf.jus.br/paginadorpub/paginador.jsp?docTP=AC\&doc/D $=627428>$. Acesso em: 01 jul. 2018. 
BRASIL. Supremo Tribunal Federal. Suspensão de Tutela Antecipada no Agravo Regimental no 223. Relator: Min. Celso de Mello. DJe: 09 abr. 2014. In: Informativo STF, 2014. Disponível em:

<http://www.stf.jus.br/portal/constituicao/artigobd.asp?item=\%201814>. Acesso em: 26 out. 2018.

BULOS, Uadi Lammêgo. Curso de Direito Constitucional. 07. ed. São Paulo: Saraiva, 2012.

CRUZ, Rodrigo da Silva. Ferdinand Lasselle x Konrad Hesse: afinal, qual é a essência de uma Constituição?. Idea Revista, Uberlândia, v. 2, n. 1, jan./dez. 2009. Disponível em: <http://www.esamcuberlandia.com.br/Revistaldea2/artigos/2010v1n2art09.pdf>. Acesso em: 01 jul. 2018.

LENZA, Pedro. Direito Constitucional Esquematizado. 16. ed. São Paulo: Saraiva, 2012.

MENDES, Gilmar Ferreira; BRANCO, Paulo Gustavo Gonet. Curso de Direito Constitucional. 7. ed. São Paulo: Saraiva, 2012.

MATSUDA, Juliana Tiemi Maruyama; PEREIRA, Elida Maria; SOUZA, Luciana Camila de. O mínimo existencial como limite à aplicação da reserva do possível aos direitos fundamentais sociais. Brasília: AGU, s.d. Disponível em:

<http://www.agu.gov.br/page/download/index/id/\%207306306>. Acesso em: 01 jul. 2018.

NASCIMENTO, Fernanda do; DAL RI, Luciene. O controle judicial das políticas públicas de saúde e a influência do neoconstitucionalismo. Revista Eletrônica Direito e Política, Programa de Pós-Graduação Stricto Sensu em Ciência Jurídica da UNIVALI, Itajaí, v. 8, n. 1, jan./abr. 2013. Disponível em:

$<$ https://siaiap32.univali.br/seer/index.php/rdp/article/download/5496/2919>. Acesso em: 01 jul. 2018.

NOVELINO, Marcelo. Direito Constitucional. 6. ed. São Paulo: Método, 2012.

PAULO, Vicente; ALEXANDRINO, Marcelo. Direito Constitucional Descomplicado. 14. ed. São Paulo: Método, 2015.

RIBEIRO, Patrícia Gomes. O direito à saúde e o princípio da reserva do possível. Revista Eletrônica Jurídico-Institucional do Ministério Público do Estado do rio grande do Norte, Natal, v. 2, n. 2, mai./jun. 2011. Disponível em:

$<$ http://www.mprn.mp.br/revistaeletronicamprn/abrir_artigo.asp?cod=16>. Acesso em: 01 jul. 2018.

ROCHA, Rosalia Carolina Kappel. A eficácia dos direitos sociais e a reserva do possível. Brasília: AGU, s.d. Disponível em:

<http://www.agu.gov.br/page/download/index/id/639910>. Acesso em: 01 jul. 2018. 
SARLET, Ingo Wolfgang; MARINONI, Luiz Guilherme; MITIDIERO, Daniel. Curso de Direito Constitucional. São Paulo: Revista dos Tribunais, 2012.

SARLET, Ingo Wolfgang; ZOCKUN, Carolina Zancaner. Notas sobre o mínimo existencial e sua interpretação pelo STF no âmbito do controle judicial das políticas públicas com base nos direitos sociais. Revista de Investigações Constitucionais, Curitiba, v. 3, n. 2 , p. 115-141, mai./ago. 2016. Disponível em:

<https://revistas.ufpr.br/rinc/article/view/46594/28767>. Acesso em: 01 jul. 2018.

SILVA, Leny Pereira da. Direito à saúde e princípio da reserva do possível. s.d. $65 \mathrm{f}$. Monografia (Especialização em Direito) - Instituto Brasiliense de Direito Público, s.d. Disponível em:

<http://www.stf.jus.br/arquivo/cms/processoAudienciaPublicaSaude/anexo/DIREITO_A_SA UDE_por_Leny.pdf>. Acesso em: 01 jul. 2018.

TOLFO, Andrei Cadore. Direitos humanos e a construção da cidadania. Vivências, Erechim, v. 9, n. 17, p. 33-43, out. 2013. Disponível em:

<http://www.reitoria.uri.br/ vivencias/Numero_017/artigos/pdf/Artigo_03.pdf >. Acesso em: 03 jul. 2018.

VASCONCELOS, Luiz Carlos Souza. Controle judicial das políticas públicas de saúde como meio de acesso à justiça. 2013. 173 f. Dissertação (Mestrado em Direito) Faculdade de Direito, Universidade Federal da Bahia, 2013. Disponível em: $<$ https://repositorio.ufba.br/ri/handle/ri/9309>. Acesso em: 01 jul. 2018.

WANG, Daniel Wei Liang. Escassez dos recursos, custos dos direitos e reserva do possível na jurisprudência do STF. Revista Direito GV, São Paulo, v. 4, n. 2, p. 539-568, jul./dez. 2008. Disponível em: <http://www.scielo.br/pdf/rdgv/v4n2/a09v4n2.pdf>. Acesso em: 01 jul. 2018. 